\title{
NOTA
}

\section{FORMAS DE APLICAÇÃO DE INOCULANTE E SEUS EFEITOS SOBRE A NODULAÇÃO DA SOJA ${ }^{(1)}$}

\author{
Santiel Alves Vieira Neto ${ }^{(2)}$, Fábio Ribeiro Pires ${ }^{(3)}$, Carlos César \\ Evangelista de Menezes ${ }^{(4)}$, June Faria Scherrer Menezes ${ }^{(5)}$, Alessandro \\ Guerra da Silva ${ }^{(5)}$, Gilson Pereira Silva ${ }^{(5)} \&$ Renato Lara de Assis ${ }^{(5)}$
}

\section{RESUMO}

Atualmente, tem-se difundido a aplicação de inoculante no sulco de semeadura na cultura da soja, mas há poucas informações que dão suporte a essa prática e comprovam sua eficiência em diferentes ambientes manejados sob plantio direto. Este trabalho teve como objetivo avaliar a viabilidade da aplicação de inoculantes na cultura da soja, via semente e sulco de semeadura, em solo já cultivado ou não com soja. Foram realizados dois experimentos em campo a partir de dezembro de 2004 em Latossolo Vermelho-Amarelo, seguindo o mesmo método e tratamentos, porém em dois locais distintos, com ou sem cultivo anterior de soja. Foram testados oito tratamentos: (1) inoculação via semente (inoculante + fungicida + micronutriente); (2) sem inoculação (fungicida + micronutriente); (3) testemunha (semente pura, sem tratamento); (4) aplicação no sulco-dose 1 (dose do inoculante recomendada no sulco); (5) aplicação no sulco-dose 2 (duas vezes a dose recomendada no sulco); (6) aplicação no sulco-dose 3 (três vezes a dose recomendada no sulco); (7) sulco-dose 1 + inoculação via semente; e (8) adubação com $N\left(200 \mathrm{~kg} \mathrm{ha}^{-1} \mathrm{~N}\right)$. Foram avaliados massa de matéria seca de nódulos e número de nódulos totais e nódulos viáveis e não-viáveis aos 30 e 75 dias após emergência. A melhor nodulação foi obtida com aplicação de inoculante + fungicida + micronutriente via semente no solo ainda não cultivado. No solo previamente cultivado com soja, destacaram-se os tratamentos uma e duas vezes a dose do inoculante no sulco. Menores valores de massa seca de nódulos na soja foram obtidos no tratamento com adubação mineral. A aplicação via sulco do inoculante

\footnotetext{
(1) Parte da Tese de Mestrado do primeiro autor, apresentada à Universidade de Rio Verde - FESURV. Recebido para publicação em novembro de 2006 e aprovado em dezembro de 2007.

(2) Engenheiro-Agrônomo, Universidade de Rio Verde - FESURV. Caixa Postal 104, Campus Universitário, CEP $75901-970$ Rio Verde (GO). E-mail: santiel@gmail.com

${ }^{(3)}$ Professor do Centro Universitário Norte do Espírito Santo, Universidade Federal do Espírito Santo - CEUNES/UFES. Rua Humberto de Almeida Franklin 257, Bairro Universitário, CEP 29933-415 São Mateus (ES). E-mail: fabiopires@ceunes.ufes.br

(4) Pesquisador da Cooperativa Agroindustrial dos Produtores Rurais do Sudoeste Goiano - COMIGO. Av. Presidente Vargas, Jardim Goiás, CEP 75901-000 Rio Verde (GO). E-mail: cmenezes@fesurv.br

(5) Professor Adjunto, FESURV. E-mails: june@fesurv.br; silvaag@fesurv.br; gilson@fesurv.br; assis@fesurv.br
} 
mostrou-se uma prática viável, em razão da semelhança dos resultados obtidos com a aplicação tradicional via semente.

Termos de indexação: inoculação, sulco de semeadura, Bradyrhizobium, Glycine $\max$.

\title{
SUMMARY: FORMS OF INOCULANT APPLICATION AND EFFECTS ON SOYBEANNODULATION
}

\begin{abstract}
Nowadays, inoculant application in the sowing furrow of soybean is widely used, but there is little information underlying this practice, which would prove the efficiency in different environments under no-tillage systems. This study aimed to evaluate the viability of inoculant application to soybean, via seed and in-furrow, in soil never cultivated with soybean or previously cultivated with soybean. Two field experiments were carried out as of December 2004 in a Red Yellow Latosol (Oxisol), using the same methodology and applying the same treatments, at two different sites, with or without previous soybean cultivation. Eight treatments were tested: (1) seed inoculation (inoculant + fungicide + micronutrient), (2) without inoculation (fungicide + micronutrient), (3) control (pure seed without treatment), (4) in-furrow application dose 1 (recommended dose of inoculant in the furrow), (5) in-furrow application dose 2 (the double of the recommended dose in the furrow), (6) furrow application dose 3 (three times the recommended dose in the furrow), (7) furrowdose $1+$ seed inoculation, and (8) $N$ fertilization $\left(200 \mathrm{~kg} \mathrm{ha}^{-1} \mathrm{~N}\right)$. The dry matter mass of the nodules, the number of total nodules and viable and non-viable nodules were evaluated 30 and 75 days after emergence. The treatment inoculant + fungicide + micronutrient application via seed in the non-cultivated soil resulted in the best nodulation. In the soil previously cultivated with soybean, the treatments with the simple and double inoculant dose in the furrow reached the best results. Nodule dry mass was the lowest in the treatment with mineral fertilization. In-furrow application of the inoculant seemed a viable practice due to the similarity of the results with traditional seed inoculation.
\end{abstract}

Index terms: inoculation, sowing furrow, Bradyrhizobium, Glycine max.

\section{INTRODUÇÃO}

A inoculação de Bradyrhizobium específico para a cultura da soja é uma prática indispensável em área de primeiro ano de cultivo dessa leguminosa (Reunião..., 2002). Todavia, a aplicação tradicional, via semente, nem sempre é eficiente, principalmente pela aplicação conjunta do rizóbio com fungicidas, inseticidas e micronutrientes, que contribuem para causar toxidez às bactérias e danos às vezes irreversíveis às sementes (Vargas \& Suhet, 1980).

Uma prática alternativa que tem sido difundida, inclusive com incremento da produção de grãos da soja, é a aplicação de rizóbio, pulverizado no sulco de semeadura, na mesma operação de distribuição da semente no momento de instalação da lavoura de soja (Zhang \& Smith, 1996). Diante do fato de que o rizóbio de soja apresenta facilidade de se estabelecer no solo e sobreviver com os substratos orgânicos disponíveis (Williams, 1984), a aplicação no sulco pode ser indicada para condições adversas, como solos secos e quentes ou sementes tratadas com produtos deletérios para o rizóbio (Ramos \& Ribeiro, 1993). É interessante também como alternativa de manejo, quando for necessário o uso de altas doses de inoculantes, para evitar o contato direto de fungicidas e micronutrientes com a semente, aumentando o número de células viáveis na semente, o que será fundamental para a fixação biológica de nitrogênio (FBN) (Jensen, 1987).

A diluição do inoculante na água, para aplicação no sulco de semeadura, melhora a distribuição do rizóbio na semente e no solo, afastando-o da superfície e posicionando-o onde há menor oscilação de temperatura e umidade, ficando, portanto, melhor localizado para infectar as raízes da soja (Greenfield, 1991; Voss, 2002).

Quando a inoculação é feita apenas na semente de soja, a nodulação inicial ocorre nos primeiros pêlos radiculares (Dart, 1977) e degenera-se antes da completa formação de grãos - processo esse que ocorre no período crítico de demanda de nitrogênio pela planta de soja (Vargas et al., 1982). Os nódulos formados posteriormente nas raízes, em solo com população estabelecida de rizóbio, prolongam o período de FBN na soja (Ciafardini \& Barbieri, 1987). Eventualmente, em campo nativo, a inoculação no solo feita no sulco poderia propiciar essa nodulação secundária (Voss, 2002), favorecendo o estabelecimento de rizóbios no solo e o incremento na nodulação. 
Alguns trabalhos avaliaram a inoculação no sulco de semeadura/plantio, com resultados que encorajam o emprego dessa técnica com ervilha (Jensen, 1987; Begum et al., 2001), feijão (Ramos \& Ribeiro, 1993) e soja (Smith et al., 1981; Chamber \& Montes, 1982; Duningan et al., 1984; Zhang \& Smith, 1996, 1997; Voss, 2002; Farias Neto et al., 2006). Por sua vez, Greenfield (1991) verificou que a produção de sementes e a nodulação não foram incrementadas com a aplicação de inoculante no sulco.

Independentemente da forma de aplicação do inoculante, sabe-se que os ganhos em produtividade decorrentes da inoculação, em áreas já cultivadas anteriormente com soja, são menos expressivos do que os obtidos em solos de primeiro ano (Zhang \& Smith, 1997; Campos, 1999; Campos \& Gnatta, 2006). Não obstante, têm-se observado ganhos médios de 4,5\% no rendimento de grãos com a inoculação em áreas já cultivadas com essa leguminosa (Embrapa, 2003). Como a soja é uma leguminosa introduzida e uma das poucas espécies que se associam com Bradyrhizobium japonicum, é pouco provável a ocorrência natural dessa bactéria em solos ainda não cultivados com soja. Entretanto, apesar da dificuldade de estabelecimento de novas estirpes de rizóbio em relação às nativas do solo (Duningan et al., 1984; Evans, 2005), há possibilidade de que algumas das estirpes introduzidas no solo, juntamente com as sementes ou por meio de inoculação artificial, sobrevivam e se naturalizem (Vargas et al., 1994; Lima et al., 1998).

A dificuldade de introdução de novas estirpes para a cultura da soja em áreas com populações estabelecidas é amplamente relatada em experimentos realizados nos Estados Unidos (Duningan et al., 1984; Singleton \& Tavares, 1986). Já no Brasil, há relatos de resposta à reinoculação, resultando em incrementos no rendimento da soja, mesmo em solos com número elevado de células de Bradyrhizobium, em experimentos nos Cerrados, em Planaltina - DF (Vargas et al., 1992, 1994; Vargas \& Hungria, 1997) e no Paraná (Hungria et al., 1996). Todos esses experimentos, porém, foram realizados sob sistema de plantio convencional.

A maior parte das áreas com soja, todavia, é cultivada no sistema plantio direto (SPD), que promove um ambiente ecológico diferenciado daquele do sistema convencional, particularmente nos primeiros centímetros do solo, cujas reduções na temperatura e nas oscilações térmicas e incremento na umidade do solo favorecem a atividade microbiana (Campos \& Gnatta, 2006). Os benefícios são também verificados na simbiose rizóbio-leguminosa, constatando-se, no caso da soja, maior número de células e diversidade de Bradyrhizobium, maior número e massa nodular, distribuição mais profunda dos nódulos no perfil do solo e taxas mais elevadas de FBN (Hungria, 1999).

Pelo exposto, a aplicação de inoculante no sulco, junto à semeadura da soja em SPD, poderia resultar no incremento da nodulação, pois posicionaria o rizóbio de forma mais concentrada e ao alcance das raízes, logo após a emergência da plântula (Voss, 2002). Por outro lado, com o pequeno revolvimento do solo proporcionado na semeadura, a partir do momento em que as raízes se aprofundarem além da camada de deposição do inoculante, poderá haver menor contato com os rizóbios e, conseqüentemente, menor FBN.

Há poucas informações disponíveis a respeito dos efeitos da aplicação do inoculante no sulco de semeadura em comparação ao procedimento de misturá-lo à semente, assim como a comparação entre os seus efeitos em áreas já cultivadas e não-cultivadas. Assim, este trabalho teve como objetivo avaliar a viabilidade da aplicação de inoculante na cultura da soja, via semente e sulco de semeadura, em solo já cultivado e em solo não cultivado com a cultura da soja.

\section{MATERIAL E MÉTODOS}

Em dezembro de 2004, foram realizados dois experimentos em campo no município de Rio Verde GO, seguindo o mesmo método e tratamentos, em dois locais distintos quanto ao histórico de cultivo: na estação experimental do Centro Tecnológico da Cooperativa Agroindustrial dos Produtores Rurais do Sudoeste Goiano (S $17^{\circ} 46$ ' 443 ”, W 05102 ' 008 ” e altitude de $853 \mathrm{~m}$ ), em área com histórico de vários anos de cultivo de soja (AC); e em uma propriedade particular, em área de pastagem, sem cultivo anterior com a cultura da soja (ANC), (S $17^{\circ} 42^{\prime} 589$ ”, W $50^{\circ} 56$ ' 661 " e altitude de $825 \mathrm{~m}$ ).

Amostras dos solos das áreas experimentais foram submetidas à caracterização química e granulométrica (Quadro 1). Os solos foram classificados como Latossolo Vermelho-Amarelo de acordo com o Sistema Brasileiro de Classificação de Solos (Embrapa, 1999). A precipitação pluvial foi monitorada durante toda a condução do experimento (Figura 1).

Antes da implantação do experimento, avaliou-se a população inicial de rizóbios nos solos dos dois locais de experimentação, por meio do método do Número Mais Provável de Células, por infecção em plantas de soja em vasos, com três repetições (vasos), na TURFAL (Indústria e Comércio de Produtos Biológicos e Agronômicos Ltda), de acordo com a metodologia descrita no Protocolo da Relare (2001). O número de células por g de solo foi de aproximadamente 3,14 x $10^{4}$ e $1,05 \times 10^{2}$, para a AC e ANC, respectivamente. Na mesma oportunidade, foi analisada também a população de rizóbios nos inoculantes.

Foram estabelecidos oito tratamentos, seguindo o delineamento experimental de blocos ao acaso, com cinco repetições: (1) semente (inoculante + fungicida + micronutriente); (2) semente (fungicida + micronutriente); (3) testemunha (semente pura); (4) 
Quadro 1. Caracterização química e granulométrica dos solos das áreas experimentais

\begin{tabular}{|c|c|c|}
\hline Atributo & $\begin{array}{c}\text { Área } \\
\text { cultivada }\end{array}$ & $\begin{array}{l}\text { Área não } \\
\text { cultivada }\end{array}$ \\
\hline $\mathrm{pH}\left(\mathrm{CaCl}_{2}\right)$ & 4,95 & 5,20 \\
\hline $\mathrm{Ca}\left(\mathrm{cmol}_{\mathrm{c}} \mathrm{dm}^{-3}\right)$ & 2,71 & 2,83 \\
\hline $\mathrm{Mg}\left(\mathrm{cmol}_{\mathrm{c}} \mathrm{dm}^{-3}\right)$ & 0,45 & 0,55 \\
\hline $\mathrm{Al}\left(\mathrm{cmol}_{\mathrm{c}} \mathrm{dm}^{-3}\right)$ & 0,05 & 0,04 \\
\hline $\mathrm{H}+\mathrm{Al}\left(\mathrm{cmol}_{\mathrm{c}} \mathrm{dm}^{-3}\right)$ & 3,00 & 4,60 \\
\hline $\mathrm{K}\left(\mathrm{mg} \mathrm{dm}^{-3}\right)$ & 52,8 & 54,70 \\
\hline $\mathrm{P}\left(\mathrm{mg} \mathrm{dm}^{-3}\right)$ & 6,75 & 3,50 \\
\hline $\operatorname{MO}\left(\mathrm{g} \mathrm{dm}^{-3}\right)$ & 24,25 & 39,80 \\
\hline $\mathrm{CTC}\left(\mathrm{cmol}_{\mathrm{c}} \mathrm{dm}^{-3}\right)$ & 5,95 & 7,50 \\
\hline $\mathrm{SB}\left(\mathrm{cmol}_{\mathrm{c}} \mathrm{dm}^{-3}\right)$ & 2,95 & 3,91 \\
\hline V (\%) & 49,60 & 45,95 \\
\hline Areia $\left(\mathrm{g} \mathrm{kg}^{-1}\right)$ & 535 & 365 \\
\hline Silte $\left(\mathrm{g} \mathrm{kg}^{-1}\right)$ & 67 & 166 \\
\hline Argila $\left(\mathrm{g} \mathrm{kg}^{-1}\right)$ & 398 & 469 \\
\hline
\end{tabular}

$\overline{\text { Os resultados da análise de solo são expressos por volume de }}$ terra fina seca ao ar (TFSA).

sulco - dose 1 (dose recomendada no sulco); (5) sulco dose 2 (duas vezes a dose recomendada no sulco); 6 ) sulco - dose 3 (três vezes a dose recomendada no sulco); (7) sulco (dose 1 no sulco) e semente (dose 1); e (8) adubação com $\mathrm{N}$ fertilizante $\left(200 \mathrm{~kg} \mathrm{ha}^{-1} \mathrm{~N}\right)$.

Nos tratamentos em que a inoculação foi realizada via semente, utilizou-se o inoculante turfoso (Glycimax ${ }^{\mathrm{R}}$ ), com as estirpes de Bradyrhizobium elkanii SEMIA 587 e 5019, em população bacteriana de $3,0 \times 10^{9}$ cels g $^{-1}$, de acordo com o método-padrão. Nos tratamentos em que a inoculação foi realizada via sulco de semeadura, foi utilizado inoculante líquido (Rhizomax ${ }^{\mathrm{R}}$ ), com as estirpes de B. japonicum SEMIA 5079 e 5080, na concentração bacteriana de $2,0 \times 10^{9}$ cels $\mathrm{mL}^{-1}$. A dose recomendada deste inoculante é a aplicação de 3,0 mL em $2 \mathrm{~L}$ de água.
Após o preparo, cada tratamento foi pulverizado com volume de calda equivalente a $100 \mathrm{~L} \mathrm{ha}^{-1}$ no sulco anteriormente aberto, que já continha as sementes, utilizando-se um pulverizador costal pressurizado com $\mathrm{CO}_{2}$, acoplado com barra, com quatro bicos de pulverização tipo leque XR110.02, espaçados de 0,5 m; cada bico do pulverizador cobria o perfil de um sulco de semeadura. Em seguida, os sulcos foram cobertos com uma camada de aproximadamente $3 \mathrm{~cm}$ de solo. As inoculações recomendadas foram determinadas para obtenção de uma população aproximadamente equivalente de inoculantes por hectare de soja, nas duas estirpes.

Com exceção do tratamento 3 (semente pura), todos os outros foram tratados com o fungicida Carbendazim (30 $\mathrm{g} \mathrm{ha}^{-1}$ de i.a.) + Thiram $\left(70 \mathrm{~g} \mathrm{ha}^{-1}\right.$ de i.a.) e micronutrientes Co $\left(5 \mathrm{~g} \mathrm{ha}^{-1}\right)+$ Mo $\left(25 \mathrm{~g} \mathrm{ha}^{-1}\right)$. O fertilizante nitrogenado foi aplicado em duas parcelas, ambas como uréia. Na primeira foram aplicados $100 \mathrm{~kg} \mathrm{ha}{ }^{-1}$ de $\mathrm{N}$ na semeadura, distribuídos manualmente cerca de $2 \mathrm{~cm}$ acima e ao lado das sementes. Aos 30 dias após a emergência (DAE) da plântula, foi feita a aplicação remanescente em cobertura.

Os experimentos foram implantados em 3/12/2004 e em 10/12/2004, para os experimentos AC e ANC, respectivamente. A abertura dos sulcos e a adubação de base, utilizando-se $370 \mathrm{~kg} \mathrm{ha}^{-1}$ da fórmula 02-2018 , foram feitas por uma semeadora-adubadora de seis linhas. Portanto, cada tratamento recebeu $7,4 \mathrm{~kg} \mathrm{ha}^{-1}$ de $\mathrm{N}$, no plantio. Logo depois, foi realizada a semeadura utilizando semeadora portátil de uma linha, com a variedade de soja MGBR 46 (Conquista), distribuindo-se 25 sementes por metro, obtendo-se um estande final de 19 plantas por metro. As parcelas experimentais tiveram dimensões de $4,0 \mathrm{~m}$ de comprimento x 6,0 m de largura (12 linhas espaçadas de $0,50 \mathrm{~cm}$ ). As avaliações foram realizadas nas seis linhas centrais de cada parcela, descartando-se $1 \mathrm{~m}$ de bordadura (área útil de $6 \mathrm{~m}^{2}$ ). $\mathrm{O}$ experimento foi conduzido realizando-se os tratos fitossanitários necessários e recomendados para a cultura na região.

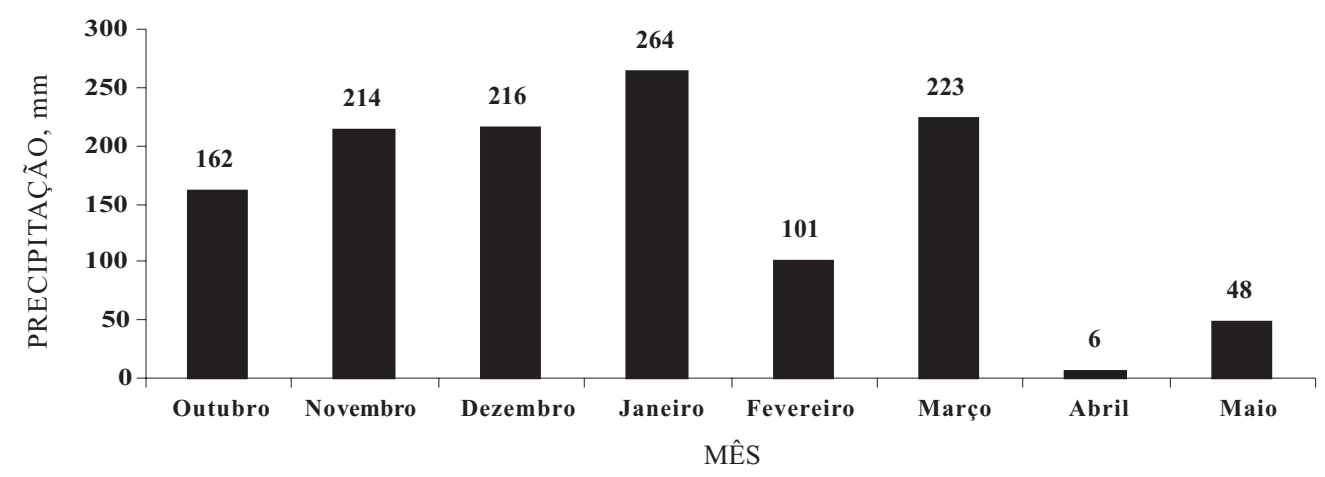

Figura 1. Precipitação mensal ocorrida durante a condução do experimento, de outubro de 2004 a maio de 2005. Rio Verde, GO, 2006. 
Aos 75 DAE, foram avaliados o número de nódulos totais (NNT), número de nódulos viáveis (NNV), número de nódulos não-viáveis (NNN) e massa seca de nódulos (MSN). Essas determinações foram feitas coletando-se 10 plantas por parcela, com raízes intactas, na terceira linha de um dos lados da parcela. A coleta foi realizada por meio da abertura de minitrincheiras, retirando-se blocos intactos de solo, contendo as raízes das plantas. Estas foram acondicionadas em sacos plásticos e transportadas para o Laboratório de Análise de Solos e Folhas FESURV Universidade de Rio Verde. Após separação e lavagem das raízes, foram retirados todos os nódulos presentes, porém somente foram avaliados os nódulos com $2 \mathrm{~mm}$ ou mais de diâmetro; para as determinações de viabilidade, os nódulos foram seccionados ao meio com estilete e foi identificada a coloração rósea. A data de 75 DAE foi escolhida por coincidir com o início do enchimento de grãos - período esse em que ocorre a maior demanda do nitrogênio.

Os dados foram submetidos à análise de variância, e os dois experimentos foram analisados conjuntamente. Quando o teste $\mathrm{F}$ foi significativo a $5 \%$, as médias dos tratamentos foram comparadas pelo teste de Tukey a $5 \%$.

\section{RESULTADOS E DISCUSSÃO}

Os tratamentos de inoculação e as duas áreas afetaram significativamente as características avaliadas. Na área com histórico de vários anos de cultivo de soja (AC), os maiores valores de NNT foram observados no tratamento que recebeu inoculante no sulco na dose-padrão recomendada, sem, no entanto, diferir estatisticamente dos outros três tratamentos que também envolveram a aplicação de inoculante via sulco de semeadura (Quadro 2). Os tratamentos com inoculação via semente e também a testemunha tiveram desempenho intermediário, sendo os menores valores encontrados na adubação com $\mathrm{N}$ fertilizante. Este último também resultou em menor NNT nas raízes das plantas na área sem cultivo anterior com essa leguminosa (ANC), porém, nessa condição, o melhor tratamento foi obtido com a aplicação via semente, misturada ao fungicida e micronutriente. Os demais tratamentos não diferiram entre si.

Os melhores resultados obtidos na AC com a aplicação via sulco de semeadura podem estar relacionados às condições mais favoráveis para o estabelecimento do Bradyrhizobium no SPD (Hungria, 1999; Voss, 2002), em termos de temperatura, umidade, fontes de carbono e estruturação do solo, decorrentes do não-revolvimento do solo e da cobertura proporcionada pelos resíduos vegetais na superfície. Nessa situação, o inoculante parece estar mais bem localizado para infectar as raízes da soja (Greenfield, 1991). Considerando que são necessários alguns anos para o equilíbrio do SPD e como a soja na ANC foi cultivada pela primeira vez nesse sistema numa área que antes era ocupada por pastagem, as características do SPD que podem favorecer a nodulação ainda não teriam se tornado perenes no solo. Por essa razão, a aplicação do inoculante via semente parece ter sido a condição que possibilitou maior contato do Bradyrhizobium com a semente na ANC. Salienta-se ainda que, na região de Cerrado, as condições para

Quadro 2. Número de nódulos totais e número de nódulos viáveis avaliados em raízes de soja, aos 75 dias após emergência, cujas sementes foram submetidas a diferentes tratamentos de inoculação, em área com histórico de vários anos de cultivo da soja e em área sem cultivo anterior com esta a cultura

\begin{tabular}{|c|c|c|c|c|}
\hline \multirow{3}{*}{ Tratamento } & \multicolumn{2}{|c|}{ Número de nódulos totais } & \multicolumn{2}{|c|}{ Número de nódulos viáveis } \\
\hline & \multicolumn{4}{|c|}{ Área } \\
\hline & Cultivada & Não-cultivada & Cultivada & Não-cultivada \\
\hline & \multicolumn{4}{|c|}{$\mathrm{N}^{\mathrm{o}} /$ plantas } \\
\hline 1. Semente (inoculante + fungicida + micronutriente) & $42,9 \mathrm{Ca}$ & $28,6 \mathrm{Ab}$ & $33,7 \mathrm{Ca}$ & $24,2 \mathrm{Ab}$ \\
\hline 2. Semente (fungicida + micronutriente) & $43,8 \mathrm{BCa}$ & $14,7 \mathrm{Bb}$ & $34,5 \mathrm{BCa}$ & $11,3 \mathrm{Cb}$ \\
\hline 3. Testemunha (semente pura, sem tratamento) & $42,4 \mathrm{Ca}$ & $21,1 \mathrm{Bb}$ & $32,1 \mathrm{Ca}$ & $16,3 \mathrm{BCb}$ \\
\hline 4. Sulco - dose 1 (dose recomendada) & $50,7 \mathrm{Aa}$ & $16,4 \mathrm{Bb}$ & $40,7 \mathrm{Aa}$ & $14,1 \mathrm{BCb}$ \\
\hline 5. Sulco - dose 2 (duas vezes a dose recomendada) & $49,9 \mathrm{ABa}$ & $18,7 \mathrm{Bb}$ & $39,6 \mathrm{Aba}$ & $16,3 \mathrm{BCb}$ \\
\hline 6. Sulco - dose 3 (três vezes a dose recomendada) & $45,6 \mathrm{ABCa}$ & $19,9 \mathrm{Bb}$ & $37,0 \mathrm{ABCa}$ & $17,5 \mathrm{Bb}$ \\
\hline 7. Sulco (dose 1$)$ e semente (dose 1$)$ & $45,0 \mathrm{ABCa}$ & $20,8 \mathrm{Bb}$ & $34,6 \mathrm{BCa}$ & $17,5 \mathrm{Bb}$ \\
\hline 8. Adubação com $\mathrm{N}$ fertilizante (200 kg ha-1) & $16,3 \mathrm{Da}$ & $5,9 \mathrm{Cb}$ & $10,8 \mathrm{Da}$ & $3,2 \mathrm{Db}$ \\
\hline
\end{tabular}

Médias seguidas de mesma letra maiúscula na coluna e mesma letra minúscula na linha, para uma mesma variável, não diferem entre si pelo teste de Tukey a $5 \%$. 
desenvolvimento da população de rizóbio no solo são menos favoráveis que na região Sul, por exemplo, devido a maior acidez do solo, baixa fertilidade e altas temperaturas. Somando-se a isso o fato de o plantio direto naquela região não alcançar o mesmo nível de cobertura do solo e, conseqüentemente, menor aporte de carbono orgânico, a sobrevivência do rizóbio pode ser dificultada, indicando a necessidade de reinoculação, visando manter populações de rizóbio adequadas no solo.

Em trabalho conduzido por Voss (2002), em campo nativo, a nodulação inicial foi maior com a inoculação na semente, seguida pelo tratamento inoculação no sulco de semeadura, e ambos foram superiores à testemunha sem inoculação, em que poucas plantas apresentaram um nódulo. A inoculação no sulco de semeadura resultou em esverdeamento menos intenso nas folhas, com muitas plantas amareladas entre outras mais verdes, indicando que as raízes de muitas plantas demoraram para ser infectadas pelo rizóbio, neste tratamento. Esses sintomas foram ainda mais intensos na testemunha. Entretanto, esse comportamento não foi observado no presente trabalho, notando-se desenvolvimento normal de todas as plantas, em todos os tratamentos. A explicação pode estar relacionada à precipitação adequada nos dois primeiros meses de condução do experimento, apesar do déficit ocorrido em fevereiro (Figura 1).

Comparando o NNT nas duas condições experimentais, verifica-se que em todas as formas de aplicação de inoculante e também na testemunha e na adubação mineral, a AC foi significativamente superior à $\mathrm{ANC}$, apresentando, em alguns casos, cerca de três vezes mais nódulos por planta. O baixo incremento na nodulação na ANC fica ainda mais evidente quando se comparam as testemunhas nas duas áreas, percebendo-se claramente o papel das estirpes de $B$. japonicum já estabelecidas na $\mathrm{AC}$ e a dificuldade de estabelecimento em solo ainda não cultivado com soja, notadamente em razão da competição com o rizóbio nativo do solo (Evans, 2005). $\mathrm{O}$ resultado obtido reafirma a necessidade de inoculação da soja em áreas de primeiro cultivo (Reunião..., 2002) e sua reinoculação nos anos seguintes, para permitir a sobrevivência e a naturalização da população de Bradyrhizobium em níveis desejáveis e eficientes no solo. Essa condição foi alcançada por Dunigan et al. (1984) após três anos de intensa inoculação do solo com estirpes nãoindígenas de Rhizobium japonicum, o que possibilitou o permanente estabelecimento dessa estirpe no solo, a qual, um vez estabelecida, tornou-se competitiva com os rizóbios nativos do solo, e a cada ano formou-se maior percentagem de nódulos nas raízes de soja.

A resposta positiva à reinoculação, mesmo em solos com número elevado de células de Bradyrhizobium, está em concordância com Vargas et al. (1992,1994) e Vargas \& Hungria (1997), no Distrito Federal, e com Hungria et al. (1996), no Paraná. Por outro lado, discorda de Campos (1999) e Campos \& Gnatta (2006), que não obtiveram resultados significativos com a inoculação em área já cultivada com a soja, no Rio Grande do Sul.

O NNV por planta teve comportamento muito semelhante ao observado no NNT (Quadro 2). Na AC, a aplicação no sulco-dose 1 foi novamente a que resultou em maior NNV, e a aplicação de $\mathrm{N}$ fertilizante teve o pior desempenho. Na ANC, como observado no NNT, os tratamentos com a aplicação de inoculante + fungicida + micronutriente via semente e a adubação com $\mathrm{N}$ fertilizante foram os que resultaram em maior e menor NNV, respectivamente. Comparando-se as áreas experimentais, a viabilidade dos nódulos foi maior em todos os tratamentos quando a soja foi cultivada em área com histórico de plantio anterior dessa espécie (Quadro 2), concordando com os dados de NNT, inclusive na testemunha e no tratamento com $\mathrm{N}$ fertilizante, o que indica a existência de melhores condições para nodulação da soja nessa área (Hungria et al., 1996; Voss, 2002).

$\mathrm{Na}$ área experimental sem cultivo anterior com a soja, nas variáveis NNT e NNV, percebe-se que a mistura inoculante + fungicida + micronutriente via semente foi o tratamento que positivamente mais se destacou. Os possíveis prejuízos à germinação e, ou, à nodulação, em razão do uso de diferentes produtos juntos na semente, do volume líquido adicionado e da presença de possíveis produtos tóxicos às estirpes de soja (Ramos \& Ribeiro, 1993), não ocorreram nas condições experimentais deste estudo e também não foram observados por Campos \& Gnatta (2006) em experimento realizado no Rio Grande do Sul durante três anos agrícolas, onde os resultados mostraram que o uso de fungicidas e fertilizantes com Co e Mo não afetou o desempenho do inoculante. No presente trabalho, a ausência de toxicidade ocorreu, possivelmente, por ter sido respeitada a quantidade de calda (inoculante + fungicida + micronutriente) máxima aconselhável para mistura em sementes e também em razão de o plantio ter sido efetuado logo após a inoculação das sementes, não prejudicando, assim, sua germinação. Outro aspecto a ser mencionado é que a turfa tem papel importante na proteção do Bradyrhizobium por ocasião da inoculação e após esta; com o uso de inoculantes líquidos, todavia, a sobrevivência do Bradyrhizobium é ainda mais reduzida no solo (Albino \& Campo, 2001). Essa talvez seja a explicação para o fato de que na ANC, cultivada com soja pela primeira vez, a inoculação via semente (tratamento 1), na qual foi utilizado inoculante turfoso, tenha apresentado o melhor desempenho. Já na AC, cujas condições de estabelecimento das estirpes são mais favoráveis em razão do histórico de cultivo da soja (Embrapa, 2003; Evans, 2005), a aplicação do inoculante no sulco de semeadura, na forma líquida, propiciou maior nodulação.

Os tratamentos de inoculação não interferiram no NNN, nas duas áreas, excetuando-se o fornecimento 
de $\mathrm{N}$ fertilizante na área com histórico de cultivo com a soja, que resultou em menor NNN em relação aos demais (Quadro 3). No entanto, o \%NNN em relação ao NNT, em cada tratamento, mostra que a adubação mineral com $\mathrm{N}$ prejudicou não apenas o NNT (Quadro 2), mas também interferiu negativamente na viabilidade dos nódulos, notadamente na área nãocultivada com soja (Quadro 3). Na AC, o tratamento 8 diferiu apenas da aplicação no sulco nas três doses testadas, as quais apresentaram, em média, 19,7\% de NNN.

A viabilidade dos nódulos é afetada por condições de baixa fertilidade do solo e elevadas doses de nitrogênio combinado (Lima et al., 1998). O primeiro fator, provavelmente, não foi impedimento para o estabelecimento dos rizóbios, pois, apesar do baixo nível inicial de fertilidade nos dois solos (Quadro 1), ambos foram corrigidos e adubados, uniformizandose as condições para favorecer a nodulação nas duas áreas. $\mathrm{O} \mathrm{N}$ fornecido na forma de fertilizante, por sua vez, parece ter sido um fator relevante, interferindo negativamente na viabilidade dos nódulos, principalmente na área onde o estabelecimento das estirpes inoculadas se deu pela primeira vez (ANC), concordando com os autores supracitados. A adição de Mo antes da inoculação também pode reduzir o número de células viáveis de Bradyrhizobium na semente, em relação à testemunha (Albino \& Campo, 2001). Contudo, pelos resultados observados nos tratamentos que envolveram a aplicação de micronutriente na semente, essa aplicação não afetou a sobrevivência do Bradyrhizobium.

Seguindo a tendência das variáveis NNT e NNV, a comparação entre AC e ANC mostra que o NNN foi maior na área já cultivada com a soja, em todos os tratamentos (Quadro 3). Contrariamente a essa observação, não houve diferença entre os tratamentos quando as duas áreas experimentais foram comparadas quanto à \%NNN, que só diferiu no tratamento com $\mathrm{N}$ fertilizante. Para este último, o maior percentual foi encontrado na área ocupada anteriormente com pastagem, levando à constatação de que, nessa condição, o estabelecimento das estirpes de Bradyrhizobium pode ser ainda mais difícil quando é fornecido às plantas $\mathrm{N}$ na forma mineral.

$\mathrm{O}$ fato de tanto $\mathrm{AC}$ quanto $\mathrm{ANC}$ apresentarem estatisticamente o mesmo \%NNN, mesmo havendo diferenças, em valores médios, no NNN por planta (Quadro 3), indica que a distinção nos resultados desta variável se deve ao NNT, contabilizados nas raízes das plantas de soja, nas duas áreas experimentais (Quadro 2). Provavelmente, a semelhança de comportamento entre os tratamentos com inoculação quanto ao NNN na AC, inclusive naquele com semente pura (Quadro 3), ocorreu por se tratar de um solo já cultivado com soja há vários anos e por possuir, com isso, uma população elevada de rizóbios já estabelecida (Campo et al., 2003), diferindo, todavia, dos resultados encontrados por Vargas et al. (1992), Hungria et al. (1996) e Vargas Hungria (1997).

Quanto à MSN, os tratamentos tiveram resultados semelhantes, excetuando-se a adubação com $\mathrm{N}$ fertilizante na $\mathrm{AC}$, que se mostrou, novamente, inferior aos demais (Quadro 4). Na área ANC, onde os tratamentos não diferiram estatisticamente, a adubação mineral também apresentou, em valores absolutos, as menores médias. O comportamento da MSN corrobora os resultados de Campos (1999) e

Quadro 3. Número de nódulos não-viáveis e percentagem de nódulos não-viáveis avaliados em raízes em raízes de soja, aos 75 dias após emergência, cujas sementes foram submetidas a diferentes tratamentos de inoculação, em área com histórico de vários anos de cultivo da soja e em área sem cultivo anterior com essa cultura

\begin{tabular}{|c|c|c|c|c|}
\hline \multirow{3}{*}{ Tratamento } & \multicolumn{4}{|c|}{ № de nódulos não-viáveis } \\
\hline & \multicolumn{4}{|c|}{ Área } \\
\hline & Cultivada & Não-cultivada & Cultivada & Não-cultivada \\
\hline & \multicolumn{2}{|c|}{$\ldots \mathrm{N} / \mathrm{o}$ plantas } & \multicolumn{2}{|c|}{$\%$} \\
\hline 1. Semente (inoculante + fungicida + micronutriente) & $9,3 \mathrm{Aa}$ & $4,5 \mathrm{Ab}$ & $21,5 \mathrm{ABa}$ & $15,6 \mathrm{Ba}$ \\
\hline 2. Semente (fungicida + micronutriente) & $9,3 \mathrm{Aa}$ & $3,5 \mathrm{Ab}$ & $21,3 \mathrm{ABa}$ & $23,0 \mathrm{Ba}$ \\
\hline 3. Testemunha (semente pura, sem tratamento) & $10,0 \mathrm{Aa}$ & $4,8 \mathrm{Ab}$ & $24,6 \mathrm{ABa}$ & $22,8 \mathrm{Ba}$ \\
\hline 4. Sulco - dose 1 (dose recomendada) & $10,1 \mathrm{Aa}$ & $2,3 \mathrm{Ab}$ & $19,9 \mathrm{Ba}$ & $13,9 \mathrm{Ba}$ \\
\hline 5. Sulco - dose 2 (duas vezes a dose recomendada) & $10,3 \mathrm{Aa}$ & $2,4 \mathrm{Ab}$ & $20,6 \mathrm{Ba}$ & $13,0 \mathrm{Ba}$ \\
\hline 6. Sulco - dose 3 (três vezes a dose recomendada) & $8,5 \mathrm{Aa}$ & $2,4 \mathrm{Ab}$ & $18,7 \mathrm{Ba}$ & $12,1 \mathrm{Ba}$ \\
\hline 7. Sulco (dose 1) e semente (dose 1$)$ & $10,4 \mathrm{Aa}$ & $3,3 \mathrm{Ab}$ & $22,8 \mathrm{ABa}$ & $16,0 \mathrm{Ba}$ \\
\hline 8. Adubação com N fertilizante $\left(200 \mathrm{~kg} \mathrm{ha}^{-1}\right)$ & $5,5 \mathrm{Ba}$ & $2,7 \mathrm{Ab}$ & $33,5 \mathrm{Ab}$ & $43,1 \mathrm{Aa}$ \\
\hline
\end{tabular}

Médias seguidas de mesma letra maiúscula na coluna e mesma letra minúscula na linha não diferem entre si pelo teste de Tukey a $5 \%$. 
Quadro 4. Massa seca de nódulos avaliados em raízes de soja, aos 75 dias após emergência, cujas sementes foram submetidas a diferentes tratamentos de inoculação, em área com histórico de vários anos de cultivo da soja e em área sem cultivo anterior com essa cultura

\begin{tabular}{|c|c|c|}
\hline \multirow[b]{2}{*}{ Tratamento } & \multicolumn{2}{|c|}{ Massa seca de nódulos } \\
\hline & Área cultivada & Área não-cultivada \\
\hline & 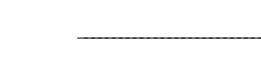 & 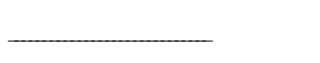 \\
\hline 1. Semente (inoculante + fungicida + micronutriente) & $0,32 \mathrm{Aa}$ & $0,31 \mathrm{Aa}$ \\
\hline 2. Semente (fungicida + micronutriente) & $0,32 \mathrm{Aa}$ & $0,28 \mathrm{Aa}$ \\
\hline 3. Testemunha (semente pura, sem tratamento) & $0,31 \mathrm{Aa}$ & $0,26 \mathrm{Ab}$ \\
\hline 4. Sulco - dose 1 (dose recomendada) & $0,34 \mathrm{Aa}$ & $0,25 \mathrm{Ab}$ \\
\hline 5. Sulco - dose 2 (duas vezes a dose recomendada) & $0,34 \mathrm{Aa}$ & $0,28 \mathrm{Ab}$ \\
\hline 6. Sulco - dose 3 (três vezes a dose recomendada) & $0,33 \mathrm{Aa}$ & $0,29 \mathrm{Aa}$ \\
\hline 7. Sulco (dose 1$)$ e semente (dosee 1$)$ & $0,32 \mathrm{Aa}$ & $0,29 \mathrm{Aa}$ \\
\hline 8. Adubação com $\mathrm{N}$ fertilizante $\left(200 \mathrm{~kg} \mathrm{ha}^{-1}\right)$ & $0,11 \mathrm{Bb}$ & $0,24 \mathrm{Aa}$ \\
\hline
\end{tabular}

Médias seguidas de mesma letra maiúscula na coluna e mesma letra minúscula na linha não diferem entre si pelo teste de Tukey a $5 \%$.

Campos et al. (2001), que verificaram que a adubação nitrogenada na soja resultou em menor número e peso de nódulos. Os resultados estão de acordo com os obtidos por Campos (1999) quanto à ausência de resposta ao aumento da dose do inoculante em área já cultivada com a soja e, ainda, confirmam aqueles encontrados por Campos \& Gnatta (2006), que concluíram que a aplicação de dose elevada de $\mathrm{N}$ reduziu a massa nodular.

Houve diferença significativa na comparação da MSN entre as duas áreas na testemunha, na aplicação de inoculante no sulco, nas doses 1 e 2 e na aplicação do $\mathrm{N}$ fertilizante (Quadro 4); neste último, a maior MSN nódulos ocorreu na $\mathrm{ANC}$, em relação à $\mathrm{AC}$. $\mathrm{O}$ aumento na MSN pode ser atribuído, provavelmente, ao direcionamento de fotoassimilados a um número reduzido de nódulos totais produzidos nesse tratamento (Quadro 2), possibilitando, assim, maior incremento por nódulo, individualmente. A menor massa de nódulos resultante dos outros três tratamentos na ANC indica que, para a variável MSN, o desempenho da nodulação em áreas de primeiro cultivo requer o uso de doses maiores, concordando com Smith et al. (1981), ou ainda um contato maior do inoculante com a semente (tratamentos que envolvem a aplicação na semente).

Os resultados mostram que, apesar da praticidade da aplicação de inoculante via sulco de semeadura, em áreas onde o cultivo da soja se dá pela primeira vez, ao contrário do que se observou para áreas já cultivadas com essa leguminosa, há necessidade de se promover maior contato do inoculante com a semente, o que parece ser obtido com a aplicação de inoculante turfoso via semente.

\section{CONCLUSÕES}

1. Em área de primeiro cultivo de soja, a aplicação de inoculante turfoso associado a fungicida e micronutriente via semente possibilita maior nodulação, enquanto, após vários anos de cultivo com soja, a melhor resposta à nodulação ocorre com aplicação de inoculante líquido no sulco de semeadura.

2. A adubação nitrogenada não é recomendada para soja devido ao prejuízo que traz à nodulação, mesmo em área de primeiro ano de cultivo.

\section{LITERATURA CITADA}

ALBINO, U.B. \& CAMPO, R.J. Efeito de fontes e doses de molibdênio na sobrevivência do Bradyhrizobium e na fixação biológica de nitrogênio em soja. Pesq. Agropec. Bras., 36:527-534, 2001.

BEGUM, A.A.; LEIBOVITCH, S.; MIGNER, P. \& ZHANG, F. Inoculation of pea (Pisum sativum L.) by Rhizobium leguminosarum bv. viceae preincubated with naringenin and hesperetin or aANClication of naringenin and hesperetin directly into soil increased pea nodulation under short season conditions. Plant Soil, 237:71-80, 2001.

CAMPO, R.J.; HUNGRIA, M.; LAURETO, E.; MIURA, L.M.; SIBALDELLI, R.N.R.; MORAIS, J.Z.; SOUZA, M.P. \& OLIVEIRA, M.C.N. Compatibilidade de aplicação de inoculantes com defensivos agrícolas e micronutrientes. In: SARAIVA, O.F., org. Resultados de pesquisa da Embrapa Soja - 2003: microbiologia de solos. Londrina, Embrapa Soja, 2004. p.45-57. (Documentos, 243) 
CAMPOS, B.H.C. Dose de inoculante turfoso para soja em plantio direto. C. Rural, 29:423-426, 1999.

CAMPOS, B.C.; HUNGRIA, M. \& TEDESCO, V. Eficiência da fixação biológica de N2 por estirpes de Bradyrhizobium na soja em plantio direto. R. Bras. Ci. Solo, 25:583-592, 2001.

CAMPOS, B.H.C. \& GNATTA, V. Inoculantes e fertilizantes foliares na soja em área de populações estabelecidas de Bradyrhizobium sob sistema plantio direto. R. Bras. Ci. Solo, 30:69-76, 2006.

CHAMBER, M.A. \& MONTES, F.J. Effects of some seeds disinfectants and methods of rhizobial inoculation on soybeans (Glycine max L. Merrill. Plant Soil, 66:353-360, 1982.

CIAFARDINI, G. \& BARBIERI, C. Effects of cover inoculation of soybean on nodulation, nitrogen fixation, and yield. Agron. J., 79:645-648, 1987.

DART, J. Infection and development of leguminous nodules. In: HARDY, R.W.F. \& SILVER, W. S. A treatise on dinitrogen fixation. Section III-BIOLOGY. New York, John Wiley \& Sons, 1977. p.307-472.

DUNINGAN, E.P.; BOLLICH, P.K.; HUNCHINSON, R.L.; HICKS, P.M.; ZAUNBRECHER, F.C.; SCOTT, S.G. \& MOWERS, R.P. Introduction and survival of an inoculant strain of Rhizobium japonicum inoculum in a field soil. Agron. J., 76:463-466, 1984.

EMPRESA BRASILEIRA DE PESQUISA AGROPECUÁRIA EMBRAPA. Sistema brasileiro de classificação de solos. Brasília, Embrapa Produção de Informação, 1999. 412p.

EMPRESA BRASILEIRA DE PESQUISA AGROPECUÁRIA EMBRAPA. Tecnologias de produção de soja na Região Central do Brasil, 2003: inoculação das sementes com Bradyrhizobium. Disponível em: <http:// sistemasdeproducao.cnptia. embrapa.br/FontesHTML/ Soja/SojaCentralBrasil2003/literatura.htm>. Acesso em: 17 de março de 2006.

EVANS, J. An evaluation of potential Rhizobium inoculant strains used for pulse production in acidic soils of southeast Australia. Aust. J. Exp. Agric., 45:257-268, 2005

FARIAS NETO, A.L.; HARTMAN, G.L.; PEDERSEN, W.L.; LI, S.; BOLLERO, G.A. \& DIERS, B.W. Irrigation and inoculation treatments that increase the severity of soybean sudden death syndrome in the field. Crop Sci., 46:2547-2554, 2006

GREENFIELD, P.L. The influence of method of inoculation and certain herbicides on nodulation and seed yield of soybeans. S. Afr. J. Plant Soil, 8:119-123, 1991.

HUNGRIA, M. Características biológicas em solos manejados sob plantio direto. In: REUNIÓN BIENAL DE LA RED LATINOAMERICANA DE AGRICULTURA CONSERVACIONISTA, 5., Florianópolis, 1999. Anais. Florianópolis, Empresa de Pesquisa Agropecuária e de Extensão Rural de Santa Catarina., 1999. CD ROM.

HUNGRIA, M.; NISHI, C.Y.M.; COHN, J. \& STACEY, G. Comparison between parental and variant soybean Bradyrhizobium strains with regard to the production of lipo-chitin nodulation signals, early stages of root infection, nodule occupancy, and $\mathrm{N}_{2}$ fixation rates. Plant Soil, 186:331-341, 1996
JENSEN, E.S. Inoculation of pea by aplication of Rhizoblium in the planting furrow. Plant Soil, 97:63-70, 1987.

LIMA, S.C.; LOPES, E.S. \& LEMOS, E.G.M. Caracterização de rizóbios (Bradyrhizobium japonicum) e produtividade da soja. Sci. Agric., 55:360-366, 1998.

RAMOS, M.L.G. \& RIBEIRO, W.Q. Effect of fungicides on survival of Rhizobium on seeds and the nodulation of bean (Phaseolus vulgaris L.). Plant Soil, 152:145-150, 1993.

REDE DE LABORATÓRIOS PARA RECOMENDAÇÃO RELARE. Padronização e difusão de tecnologia de inoculantes microbianos de interesse agrícola. Protocolo RELARE. 2001. Disponível em: <http://www.relare.org.br/ >. Acesso em: 22 março 2005.

REUNIÃO DE PESQUISA DE SOJA DA REGIÃO SUL. Indicações técnicas para a cultura da soja no Rio Grande do Sul e em Santa Catarina. 2002/2003. Cruz Alta, FUNDACEP/FECOTRIGO, 2002. 139p.

SINGLETON, P.W. \& TAVARES, J.W. Inoculation response of legumes in relation to the number and effectiveness of indigenous rhizobium population. AANCl. Environ. Microbiol., 51:1013-1018, 1986.

SMITH, R.S.; ELLIS, M.A. \& SMITH, R.E. Effect of Rhizobium japonicum inoculant rates on soybean nodulation in a tropical soil. Agron. J., 73:505-508, 1981.

VARGAS, M.A.T.; MENDES, I.C.; SUHET, A.R. \& PERES, J.R.R. Duas novas estirpes de rizóbio para a inoculação da soja. Planaltina, Empresa Brasileira de Pesquisa Agropecuária, Centro de Pesquisa Agropecuária dos Cerrados, 1992. 3p. (Comunicado Técnico, 62)

VARGAS, M.A.T.; MENDES, I.C.; SUHET, A.R. \& PERES, J.R.R. Inoculação de soja em solos de Cerrado com populações estabelecidas de Bradyrhizobium japonicum. R. Microbiol, 25:245-50, 1994.

VARGAS, M.A.T. \& HUNGRIA, M. Fixação biológica do $\mathrm{N}_{2}$ na cultura da soja. In: VARGAS, M.A.T. \& HUNGRIA, M., eds. Biologia dos solos do Cerrado. Planaltina, Empresa Brasileira de Pesquisa Agropecuária, 1997. p.297-360.

VARGAS, M.A.T. \& SUHET, A.R. Efeitos da inoculação e deficiência hídrica no desenvolvimento da soja. R. Bras. Ci. Solo, 4:17-21, 1980.

VARGAS, M.A.T.; PERES, J.R.R. \& SUHET, A.R. Adubação nitrogenada, inoculação e épocas de calagem para a soja em um solo sob Cerrado. Pesq. Agropec. Bras., 17:11271132, 1982.

VOSS, M. Inoculação de rizóbio no sulco de semeadura para soja, em um campo nativo, no norte do Rio Grande do Sul. Passo Fundo, Embrapa Trigo, 2002. 5p. html (Embrapa Trigo. Comunicado Técnico Online, 108). Disponível em: http://www.cnpt.embrapa.br/biblio/p_co108.htm

WILLIAMS, P.M. Current use of legume inoculant technology. In: ALEXANDER, M. Biological nitrogen fixation. Ecology, technology and physiology. New Work, Plenum Press, 1984. p.173-200. 
ZHANG, F. \& SMITH, D.L. Inoculation of soybean (Glycine max. (L.) Merr.) with genistein-preincubated Bradyrhizobium japonicum or genistein directly apllied into soil increases soybean protein and dry matter yield under short season conditions. Plant Soil, 179:233-241, 1996.
ZHANG, F. \& SMITH, D.L. Application of genistein to inocula and soil to overcome low spring soil temperature inhibition of soybean nodulation and nitrogen fixation. Plant Soil, 192:141-151, 1997. 